\title{
The Emergence of Epstein-Barr Virus-Related Diffuse Large B-Cell Lymphoma With Mogamulizumab
}

\author{
Lan Wang ${ }^{\mathrm{a}}$, Miriam Bargout ${ }^{\mathrm{a}}$, Jane Date Hon ${ }^{\mathrm{b}}$, Bassam Yaghmour ${ }^{\mathrm{c}}$, \\ Ann Mohrbacher ${ }^{\mathrm{a}}$, George Yaghmour ${ }^{\mathrm{a}, \mathrm{d}}$
}

Angioimmunoblastic T-cell lymphoma (AITL) is one of the most common types of $\mathrm{T}$ cell lymphomas, representing approximately $15-20 \%$ of all cases [1]. The CC chemokine receptor 4 (CCR4) is a transmembrane chemokine receptor that plays an important role in the homing and migration of T-cells to the skin, and its expression has been seen in patients with cutaneous T cell lymphomas (CTCL) and adult T-cell lymphomas (ATL). Mogamulizumab is the first humanized monoclonal antibody directed against CCR4, and is currently Food and Drug Administration (FDA)-approved in the USA for the treatment of mycosis fungoides and Sezary syndrome [2, 3]. Mogamulizumab exerts its antitumor activity through antibody-dependent cellular cytotoxicity (ADCC) against CCR4-positive malignant $\mathrm{T}$ cells and through downregulation of regulatory $\mathrm{T}$ cells (Tregs) to enhance the immune response [4, 5]. Mogamulizumab has shown promising results as both monotherapy and in combination chemotherapy in the treatment of T-cell lymphomas, including AITL, in the relapsed/refractory setting through several phase I and II studies [6]. Here, we report a case of Epstein-Barr virus (EBV)-related diffuse large B-cell lymphoma (DLBCL) that developed after the use of mogamulizumab for the treatment of relapsed AITL.

A 73-year-old female with a past medical history of eosinophilic fasciitis, presented with left axillary and left inguinal lymphadenopathy that was biopsied showing ill-defined nodular and diffuse aggregates (cluster of differentiation (CD) $3^{+}, \mathrm{CD} 4^{+}$, $\mathrm{CD}^{+} 0^{+}, \mathrm{PD}^{+}$, and $\mathrm{CD} 30$ with $10 \%$ partial expression) admixed with larger immunoblasts and prominent blood vessels, consistent with AITL. The patient was referred to our center from outside facility; we could not obtain a picture of the pathology at initial diagnosis. The patient initially opted for a trial of alternative therapy but re-presented 7 months later with extensive cutaneous disease in her arms, face, neck, and anterior chest,

Manuscript submitted December 23, 2019, accepted January 15, 2020

aDivision of Hematology, University of Southern California, Norris Comprehensive Cancer Center, Los Angeles, CA 90033, USA

bivision of Pathology, University of Southern California, Los Angeles, CA 90033, USA

'Pulmonary, Critical Care, Keck School of Medicine of University of Southern California, Los Angeles, CA 90033, USA

${ }^{\mathrm{d}}$ Corresponding Author: George Yaghmour, Division of Hematology, University of Southern California, 1441 Eastlake Ave, Los Angeles, CA 90033, USA. Email: george.yaghmour@med.usc.edu

doi: https://doi.org/10.14740/wjon1255 worsening lymphadenopathy (Fig. 1a) and fatigue. She still did not want to start conventional chemotherapy, so she was initiated on the anti-CD30 antibody drug conjugate, brentuximab, along with palliative radiation for symptomatic management. In spite of initial near clearance of all her skin lesions and most of her lymphadenopathy on brentuximab (Fig. 1b), after nine doses over 7 months, subsequent positron emission tomography-computed tomography (PET-CT) showed evidence of progression with worsening lymphadenopathy (Fig. 1c). The patient refused to have a repeated biopsy and after tumor board discussion, the patient was then started on mogamulizumab, with resolution of her skin lesions and cervical lymphadenopathy. However, repeat PET-CT after 10 doses of the mogamulizumab, showed mixed response but with the development of new hypermetabolic lymph nodes consistent with progression of disease (Fig. 1d), so the patient was referred for a clinical trial. However, prior to the first course of the trial treatment, a repeat lymph node biopsy of the left axillary lymph node showed evidence of EBV + DLBCL, without definitive evidence of her previous AITL (Fig. 2). Given the new pathology findings, the patient was started on bendamustine with rituximab, with the anti-CD79a monoclonal antibody, polatuzumab.

Although mogamulizumab has shown efficacy in patients with AITL, it also interferes with normal immune defenses relying on chemotaxis of $\mathrm{T}$ cells to areas of infection. The monoclonal antibody has been reported to cause immunopathologies such as graft-versus-host disease, especially of the skin. The immunomodulatory effects, along with the prolonged lymphopenia from mogamulizumab therapy, have been proposed to cause reactivation of viral infections such as cytomegalovirus (CMV), hepatitis B and EBV [1, 7-9]. The reactivation of EBV may, in turn, cause B-cell lymphoproliferative disorders as well as the emergence of EBV-positive DLBCL, as in our patient (Table 1, $[8,10])$.

This case implies that although mogamulizumab has efficacy against $\mathrm{T}$ cell lymphomas, the off-target effects of mogamulizumab on $\mathrm{T}$ cells normally involved in immune surveillance against virally infected cells can lead to the selective emergence of EBV-positive DLBCL. Administration of this medication requires careful monitoring and surveillance to detect emerging infections and lymphomas.

\section{Acknowledgments}

None to declare. 

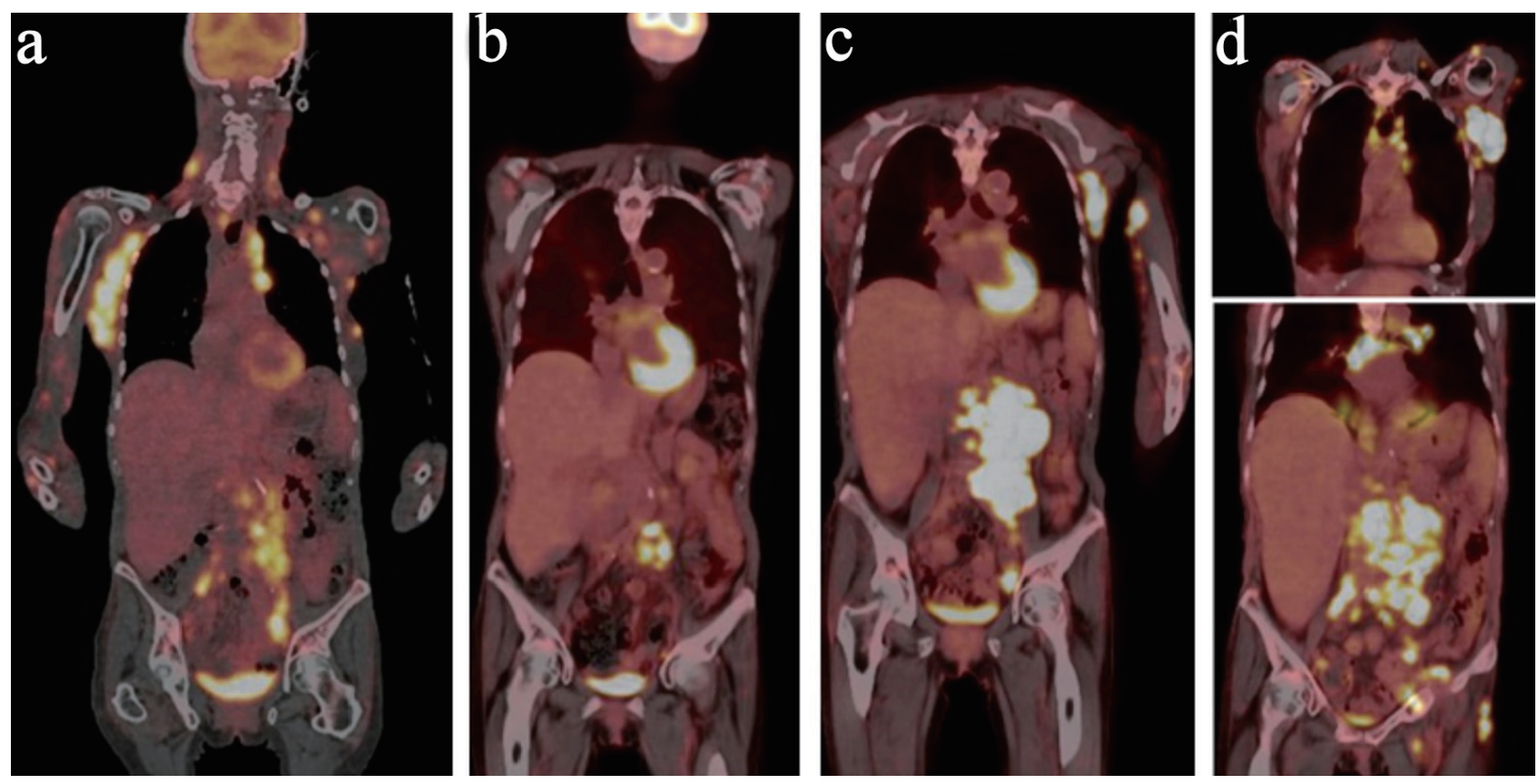

Figure 1. PET-CT panel with initial PET-CT, PET-CT with progression in February, 2019, PET-CT in May, 2019 and PET in July, 2019. (a) PET-CT at initial diagnosis. (b) PET-CT after brentuximab. (c) PET-CT with progression on brentuximab. (d) PET-CT with progression on mogamulizumab. PET-CT: positron emission tomography-computed tomography.
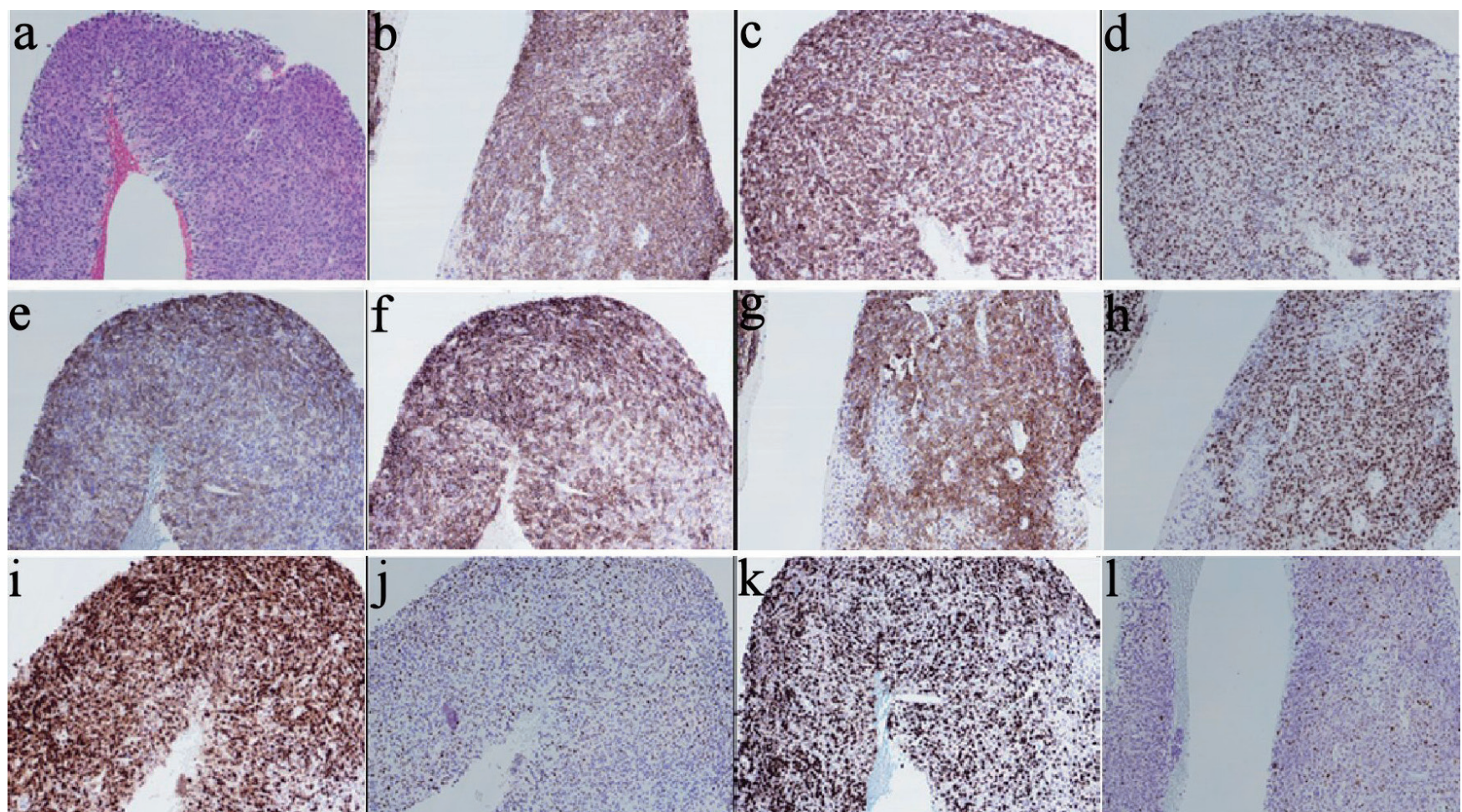

Figure 2. Pathology images/panel with EBV+ DLBCL. (a) H\&E stain showing large lymphoma cells infiltrating the tissue in sheets (× 10). (b) CD20 IHC (× 10). (c) BCL2 IHC (× 10). (d) BCL6 IHC (× 10). (e) CD21 IHC (× 10). (f) CD23 IHC (× 10). (g) CD30 $\mathrm{IHC}(\times 10)$. (h) OCT2 IHC $(\times 10)$. (i) MUM1 IHC $(\times 10)$. (j) Twenty to thirty percent of cells positive for MYC IHC $(\times 10)$. (k) High proliferation index $(80-90 \%)$ by Ki-67 IHC (× 10). (I) Patchy positive EBER-ISH (× 10). EBV: Epstein-Barr virus; DLBCL: diffuse large B-cell lymphoma; H\&E: hematoxylin and eosin stain; IHC: immunohistochemistry; ISH: in situ hybridization; CD: cluster of differentiation. 
Table 1. Summary of All Reported Patients Treated with Mogamulizumab and Developed EBV-Associated DLBCL

\begin{tabular}{|c|c|c|c|c|c|}
\hline Reference & $\begin{array}{l}\text { Number of pa- } \\
\text { tients in study }\end{array}$ & $\begin{array}{l}\text { Age } \\
\text { (years) }\end{array}$ & Line and type of therapy & $\begin{array}{l}\text { Post mogamulizumab } \\
\text { secondary malignancy }\end{array}$ & $\begin{array}{l}\text { Duration of treatment of mogamuli- } \\
\text { zumab before diagnosis of DLBCL }\end{array}$ \\
\hline $\begin{array}{l}\text { Kamachi et } \\
\text { al, } 2019[8]\end{array}$ & 1 & 83 & $\begin{array}{l}\text { One line. THP-COP (pirarubicin, } \\
\text { cyclophosphamide, vincristine, } \\
\text { and prednisolone) then THP-COP } \\
\text { combined with mogamulizumab. }\end{array}$ & $\begin{array}{l}\text { EBV-related } \\
\text { CNS DLBCL }\end{array}$ & Five cycles \\
\hline $\begin{array}{l}\text { Tanaka et al, } \\
2017[10]\end{array}$ & 1 & 66 & $\begin{array}{l}\text { Two lines. The first line: CHOP } \\
\text { (doxorubicin, vincristine, } \\
\text { cyclophosphamide and } \\
\text { prednisone). The second } \\
\text { line CHASE (etoposide, } \\
\text { cyclophosphamide, cytarabine, } \\
\text { dexamethasone). Then } \\
\text { mogamulizumab as single agent. }\end{array}$ & $\begin{array}{l}\text { EBV-related } \\
\text { CNS DLBCL }\end{array}$ & Seven cycles \\
\hline $\begin{array}{l}\text { Wang et } \\
\text { al, } 2020\end{array}$ & 1 & 73 & $\begin{array}{l}\text { One line. Brentuximab vedotin } \\
\text { (CD30 monoclonal antibodies) }\end{array}$ & $\begin{array}{l}\text { Systemic DLBCL with } \\
\text { no CNS involved }\end{array}$ & Ten cycles \\
\hline
\end{tabular}

EBV: Epstein-Barr virus; DLBCL: diffuse large B-cell lymphoma; CNS: central nervous system; CD: cluster of differentiation.

\section{Financial Disclosure}

None to declare.

\section{Conflict of Interest}

I George Yaghmour disclose Takeda, Jazz, and Astellas Board Speaker, Incyte and Jazz Advisory board. The authors do not have any conflicts of interest.

\section{Informed Consent}

Not applicable.

\section{Author Contributions}

Lan Wang, Miriam Bargout, Jane Date Hon, Bassam Yaghmour, Ann Mohrbacher, and George Yaghmour performed the research and wrote the paper. Ann Mohrbacher and George Yaghmour supervised the study.

\section{References}

1. Yabe M, Dogan A, Horwitz SM, Moskowitz AJ. Angioimmunoblastic T-Cell Lymphoma. Cancer Treat Res. 2019;176:99-126.

2. Kasamon YL, Chen H, de Claro RA, Nie L, Ye J, Blumenthal GM, Farrell AT, et al. FDA Approval summary: mogamulizumab-kpkc for mycosis fungoides and Sezary syndrome. Clin Cancer Res. 2019;25(24):7275-7280.

3. Ni X, Jorgensen JL, Goswami M, Challagundla P, Decker WK, Kim YH, Duvic MA. Reduction of regulatory T cells by Mogamulizumab, a defucosylated anti-CC chemokine receptor 4 antibody, in patients with aggressive/refractory mycosis fungoides and Sezary syndrome. Clin Cancer Res. 2015;21(2):274-285.

4. Murai K, Hiroyuki H, Sato A, Yasuro M, Mori Y, Sakuma T. Mogamulizumab monotherapy in the treatment of relapsed/refractory peripheral T-cell lymphoma or cutaneous T-cell lymphoma patients in single-institution experience. Blood. 2017;130:(Supplement 1):5179.

5. Yoshie O. Expression of CCR4 in adult T-cell leukemia. Leuk Lymphoma. 2005;46(2):185-190.

6. Ishida T, Utsunomiya A, Jo T, Yamamoto K, Kato K, Yoshida S, Takemoto S, et al. Mogamulizumab for relapsed adult T-cell leukemia-lymphoma: Updated follow-up analysis of phase I and II studies. Cancer Sci. 2017;108(10):2022-2029.

7. Ishii Y, Itabashi M, Numata A, Yamamoto W, Motohashi $\mathrm{K}$, Hagihara M, Matsumoto K, et al. Cytomegalovirus pneumonia after anti-CC-chemokine receptor 4 monoclonal antibody (Mogamulizumab) therapy in an angioimmunoblastic T-cell lymphoma patient. Intern Med. 2016;55(6):673-675.

8. Kamachi K, Shindo T, Miyahara M, Kitaura K, Akashi M, Shin IT, Suzuki R, et al. Epstein-Barr virus-related diffuse large B-cell lymphoma in mogamulizumab-treated adult T-cell leukemia with incomplete T-cell reconstitution. Int J Hematol. 2019;109(2):221-227.

9. Nakagawa M, Schmitz R, Xiao W, Goldman CK, Xu W, Yang Y, Yu X, et al. Gain-of-function CCR4 mutations in adult $\mathrm{T}$ cell leukemia/lymphoma. J Exp Med. 2014;211(13):2497-2505.

10. Tanaka H, Aoki H, Sugita Y, Shimizu R, Kiko K, Mochida H, Suzuki Y. Development of epstein-barr virus-related primary diffuse large B-cell lymphoma of the central nervous system in a patient with peripheral T-cell lymphoma, not otherwise specified after mogamulizumab treatment. Intern Med. 2017;56(20):2759-2763. 